\title{
NATIONAL INNOVATION SYSTEM AS A BASIS FOR FORMING AND IMPLEMENTING THE REGIONAL ECONOMY INNOVATION CAPACITY
}

\author{
Igor V. Antonenko \\ Volgograd State University, Volgograd, Russian Federation
}

\begin{abstract}
This paper focuses on the innovation development of regional economy within the national innovation system (NIS) which is viewed as an organizational form of implementing innovation capacity. The structural and functional approach used by the author allows distinguishing the NIS elements: science and education (research and development sector acts as an organizational form of the innovation capacity implementation), business sector (innovation commercialization sector acts as an organizational form of implementing the innovation capacity), and innovation infrastructure (knowledge transfer sector acts as an organizational form of implementing the innovation capacity). The regional innovation system (RIS) is structured on levels, functions, and subjects and is presented as a number of subsystems: first, institutional subsystem, organizational and administrative subsystem, finance and investment subsystem ('management-regulation' function ensures external opportunities and incentives for implementing the innovation capacity), second, research and development subsystem, education subsystem ('knowledge generation' function ensures internal opportunities for implementing the innovation capacity), third, infrastructure and information subsystem ('knowledge transfer' function ensures implementing the innovation capacity resource element), forth, production and technology subsystem, cluster and sector subsystem, and resource subsystem ('innovation implementation' function ensures the result of implementing the innovation capacity). The author distinguishes the elements of the innovation implementation structure in accordance with the RIS subsystems.
\end{abstract}

Key words: national innovation system, innovation capacity, regional innovation system, regional economy, knowledge generation.

Citation. Antonenko I.V. National Innovation System as a Basis for Forming and Implementing the Regional Economy Innovation Capacity. Journal of Volgograd State University. Economics, 2019, vol. 21, no. 4, pp. 99-109. (in Russian). DOI: https://doi.org/10.15688/ek.jvolsu.2019.4.10

\section{НАЦИОНАЛЬНАЯ ИННОВАЦИОННАЯ СИСТЕМА КАК ОСНОВА ФОРМИРОВАНИЯ И РЕАЛИЗАЦИИ ИННОВАЦИОННОГО ПОТЕНЦИАЛА РЕГИОНАЛЬНОЙ ЭКОНОМИКИ}

\section{Игорь Владимирович Антоненко}

Волгоградский государственный университет, г. Волгоград, Российская Федерация

Аннотация. Инновационное развитие регионального уровня рассматривается в рамках национальной инновационной системы (далее - НИС) как организационной формы реализации инновационного потенциала (далее - ИП), что позволило автору на основе структурно-функционального подхода выделить различные элементы структуры НИС. Структурному элементу НИС «наука и образование» в качестве организационной формы реализации ИП соответствует сектор НИОКР; предпринимательскому сектору - сектор коммерциализации разработок; инновационной инфраструктуре - сектор трансфера нововведений. Национальная инновационная система была структурирована по субъектам, функциям и уровням, что позволило выделить в структуре региональной инновационной системы (далее - РИС) такие подсистемы, как: во-первых, финансово-инвестиционную, институциональную, организационно-управленческую, где функция «уп- 
равление-регулирование» создает внешние возможности реализации ИП; во-вторых, образовательную и научно-исследовательскую, где функция «генерации знаний» создает внутренние возможности реализации ИП; в-третьих, информационную и инфраструктурную, где функция «передачи знаний» обеспечивает реализацию ресурсного элемента ИП; в-четвертых, кластерно-отраслевую, производственно-технологическую и ресурсную, где функция «реализации нововведений» обеспечивает результат реализации ИП, что явилось основой построения организационной структуры управления реализацией ИП на региональном уровне. Автором выделены компоненты структуры управления реализацией ИП региональной экономики в соответствии с определенными подсистемами РИС.

Ключевые слова: национальная инновационная система, инновационный потенциал, региональная инновационная система, региональная экономика, генерация знаний.

Цитирование. Антоненко И. В. Национальная инновационная система как основа формирования и реализации инновационного потенциала региональной экономики // Вестник Волгоградского государственного университета. Экономика. - 2019. - Т. 21, № 4. - С. 99-109. - DOI: https://doi.org/10.15688/ek.jvolsu.2019.4.10

\section{Введение}

В правительственном документе «Основы политики Российской Федерации в области развития науки и технологий на период до 2020 года и дальнейшую перспективу» [Национальный центр...] ставятся задачи формирования и развития целостной НИС, способной создавать стимулы для роста ИП и эффективно его использовать.

Развитие национальных и региональных инновационных систем обеспечит высокий уровень инновационной активности, появление новых форм хозяйствования, новых технологий, что позволит достигнуть устойчивых темпов экономического роста в России на современном этапе [Национальные..., 2006, с. 28].

По мнению автора, функции субъектов элементного состава НИС и ИП во многом сопоставимы, а получение, распространение и использование знаний является общей характеристикой их функционального назначения. Исходя из этого, автором исследовалась взаимосвязь субъектно-объектной структуры НИС и ИП, а также была определена степень «вовлеченности» элементов НИС в формирование и реализацию ИП.

\section{Результаты и обсуждение}

Основой анализа является концептуальная модель субъектно-объектной структуры ИП, представленная на рисунке 1 .

Согласно функциональному назначению, определенному элементу НИС соответствует определенный субъектный состав ИП. Так, элементу «Генерация знаний», в качестве орга- низационной формы развития и реализации ИП соответствует сектор НИОКР (см. табл. 1 и рис. 1); элементу «Предпринимательский сектор» - сектор коммерциализации нововведений (см. табл. 1 и рис. 1); элементу «Инновационная инфраструктура» - сектор трансфера знаний (см. табл. 1 и рис. 1).

Уровню «Управление - Регулирование», который представлен органами государственной власти, соответствует государственный сектор (см. табл. 1 и рис. 1), что способствует созданию внешних возможностей использования ИП (является первым элементом ИП), а также мотивационных стимулов к инновационной деятельности (является вторым элементом ИП).

Согласно табл. 1 элемент НИС «Генерация знаний» и соответствующий ему сектор НИОКР в качестве организационной формы реализации ИП обеспечивают экспериментальный задел для технологических инноваций.

Элемент НИС «Инновационная инфраструктура» и соответствующий ему сектор трансфера технологий мобилизуют ресурсную составляющую ИП.

Элемент НИС «Предпринимательский сектор» и соответствующий ему сектор коммерциализации нововведений обеспечивают производство инноваций.

Итак, согласно субъектно-объектной структуре ИП (см. рис. 1) связи иерархии (уровень «Управление-Регулирование») обеспечивают мотивационные стимулы реализации ИП (см. табл. 1), а элемент НИС «Генерация знаний» формирует механизм передачи знаний посредством инновационной инфраструктуры (элемент НИС «Инновационная 
И.В. Антоненко. Национальная инновационная система



Рис. 1. Концептуальная модель субъектно-объектной структуры инновационного потенциала Примечание. Составлено автором.

Таблица 1

Характеристика элементного состава НИС как организационной формы и реализации ИП

\begin{tabular}{|c|c|c|}
\hline Элемент НИС / Субъект ИП & Функции НИС & $\begin{array}{l}\text { Формирование и реализация } \\
\text { инновационного потенциала }\end{array}$ \\
\hline $\begin{array}{l}\text { «Управление - Регулирование»- Госу- } \\
\text { дарственный сектор: } \\
\text { a) органы по разработке и координации } \\
\text { инновационной политики; } \\
\text { б) финансирующие организации; } \\
\text { в) регулирующие организации }\end{array}$ & $\begin{array}{l}\text { а) формулирование иннова- } \\
\text { ционной политики; } \\
\text { б) мобилизация и распреде- } \\
\text { ление ресурсов; } \\
\text { в) создание регулирующей } \\
\text { среды и стимулов для разви- } \\
\text { тия инноваций }\end{array}$ & $\begin{array}{l}\text { 1. Создание внешних возможно- } \\
\text { стей для реализации инноваци- } \\
\text { онного потенциала. } \\
\text { 2. Формирование мотивацион- } \\
\text { ных стимулов по реализации ин- } \\
\text { новационного потенциала }\end{array}$ \\
\hline $\begin{array}{l}\text { «Генерация знаний»-Сектор НИОКР: } \\
\text { а) РАН и отраслевые НИИ; } \\
\text { б) вузы; } \\
\text { в) лаборатории }\end{array}$ & $\begin{array}{l}\text { а) проведение НИОКР и рас- } \\
\text { пределение ресурсов; } \\
\text { б) создание человеческого } \\
\text { капитала }\end{array}$ & $\begin{array}{l}\text { 3. Создание внутренних возмож- } \\
\text { ностей реализации инновацион- } \\
\text { ного потенциала посредством } \\
\text { формирования эксперименталь- } \\
\text { ного задела для дальнейшего } \\
\text { превращения их в технологиче- } \\
\text { ские инновации }\end{array}$ \\
\hline $\begin{array}{l}\text { «Инновационная инфраструктура» - } \\
\text { Сектор трансфера технологий: } \\
\text { а) ИТЦ; } \\
\text { б) ЦТТ; } \\
\text { в) консалтинговые фирмы; } \\
\text { г) бизнес-инкубаторы }\end{array}$ & $\begin{array}{l}\text { a) диффузия технологий; } \\
\text { б) развитие новых отраслей }\end{array}$ & $\begin{array}{l}\text { 4. Реализация ресурсного эле- } \\
\text { мента инновационного потен- } \\
\text { циала }\end{array}$ \\
\hline $\begin{array}{l}\text { «Предпринимательский сектор»-Сектор } \\
\text { коммерциализации нововведений: } \\
\text { a) промышленные предприятия; } \\
\text { б) инновационно-активные предприятия }\end{array}$ & $\begin{array}{l}\text { a) использование новшеств и } \\
\text { реализация нововведений }\end{array}$ & $\begin{array}{l}\text { 5. Результат реализации иннова- } \\
\text { ционного потенциала }\end{array}$ \\
\hline
\end{tabular}

Примечание. Составлено автором. 
инфраструктура»), а также создает условия развития инновационного предпринимательства (элемент НИС «Предпринимательский сектор»). Соответственно, элемент НИС «Генерация знаний» и элемент НИС «Инновационная инфраструктура» способствуют реализации ИП (элемент НИС «Предпринимательский сектор»), тем самым образуя результативную составляющую ИП (см. рис. 1).

Исследование НИС продолжим выявлением характера связей и свойств ее элементов как системы инновационной, национальной и, соответственно, региональной.

Современный этап развития хозяйственной системы характеризуется процессами регионализации экономики, что создает предпосылки для формирования относительно самостоятельных подсистем.

Региональная структура НИС характеризуется распределением ресурсов по видам (элементы структуры национальной инновационной системы «Генерация знаний», «Инновационная инфраструктура» и «Предпринимательский сектор»), стадиям исследования (элемент «Генерация знаний» структуры национальной инновационной системы), отраслям экономики и непроизводственной сферы (элемент «Предпринимательский сектор» структуры национальной инновационной системы) [Егоров и др., 2002, с. 29].

РИС необходимо рассматривать как интегральную системную характеристику состояния, условий и особенностей развития инновационной деятельности в том или ином регионе [Егорова и др., 2007, с. 66]. В связи с этим определение РИС Европейской Комиссией как «сети фирм, формирующих локальный производственный кластер вместе с институциональной инфраструктурой» [Industrial Relations..., p. 45] является, на наш взгляд, односторонним, не учитывающим особенностей инновационного развития региона.

Определяя ИП как возможности и способности воспроизводства инновационной деятельности, инновационная система региона рассматривается нами «не в виде технологических цепочек вертикально интегрированных имущественных комплексов, ведущих от НИОКР к инновациям» [Егорова и др., 2007, c. 67], а как процесс взаимодействия и обратных связей между трансакционными и трансформационными факторами, определяющими условия и способности формирования и развития ИП хозяйственной системы [Иншаков, 2002].

В связи с этим вызывает сомнение утверждение Л.К. Гуриевой [Гуриева, 2007, с. 138], что РИС является трехуровневой системой, где первый уровень - общесистемный. Второй уровень - отраслевой и поэтому РИС является функциональной подсистемой региональной отраслевой экономики, третий уровень - институциональный, то есть РИС пространственно организованная подсистема национальной инновационной системы.

На наш взгляд, отраслевой уровень может выступать как самостоятельная подсистема НИС вследствие того, что системы институтов, поддерживающие технологические инновации, в разных отраслях различны, и поэтому одной из причин выделения НИС являются межотраслевые различия между инновационными системами. Неправомерно на общесистемном уровне объединять организации, создающие и распространяющие инновации в регионе, так как функциональное назначение сегмента генерации и трансфера знаний различно, что было установлено нами ранее.

Функциональные возможности каждой подсистемы РИС индивидуальны, их состав и структура зависят от региональной специализации, уровня образования, инновационного и экономического потенциалов. Следовательно, необходимо выяснить, какие подсистемы РИС являются системообразующими (на примере ЮФО), а также выявить характер взаимодействия между ними.

Наличие ресурсов, производственных мощностей, инфраструктуры недостаточно для закрепления за территорией инновационного статуса, поэтому необходимы институциональные ориентиры деятельности, которые отражали бы цели и задачи развития региона как подсистемы НИС [Демидов и др., 2008, с. 63].

Рассматривая элементный состав НИС как организационную форму создания и реализации ИП, а РИС - как подсистему НИС, исходя из функционального назначения элементного состава национальной инновационной системы, выделим в структуре РИС соответствующие подсистемы по уровням с иерархичными связями между ними (верти- 
кальная ось) и по элементам, объединенным в блоки / компоненты (горизонтальная ось).

Институционально РИС образуется на основе управленческих воздействий и государственного регулирования инновационной деятельности, где каждая подсистема регламентируется совокупностью законодательных и нормативных актов деятельности в данном направлении и выполняемыми определенными функциями [Маренков, 2004, с. 48].

Таким образом, вследствие того, что РИС состоит из подсистем, взаимосвязанных посредством инновационной инфраструктуры и институционального воздействия государства, в структуре РИС целесообразно выделить институциональную, финансово-инвестиционную и организационную подсистемы, способствующие формированию внешних возможностей и мотивационных стимулов для реализации ИП.

Таким образом, в рамках государственного сектора, уровня «Управление - Регулирование» структуры инновационной системы (см. табл. 1), формируются подсистемы РИС, обеспечивающие реализацию ИП.

Вычленение научно-исследовательской подсистемы в структуре РИС обусловлено тем, что научные учреждения региона на протяжении всего инновационного цикла проводят научно-исследовательские и опытно-конструкторские работы, которые определяют возможность создания новых технологий, отраслей, инноваций, определяют специализацию инновационной системы региона, тем самым обеспечивая создание внутренних возможностей реализации ИП.

Образовательная подсистема в структуpe РИС также создает внутренние возможности реализации ИП в виде научных заделов и экспериментальной базы, обеспечивающих создание инноваций.

Вычленение инфраструктурной подсистемы обусловлено тем, что инфраструктурное обеспечение инновационной деятельности позволяет интегрировать науку и образование (элемент «Генерация знаний» структуры инновационной системы) с производством (элемент «Предпринимательский сектор» структуры инновационной системы), обеспечивая развитие всех стадий инновационной деятельности (производственно-технологических, информационных, управленческих, фи- нансовых структур), тем самым реализуя ресурсный элемент ИП.

В структуре РИС целесообразно выделить информационную подсистему, способствующую реализации ресурсного элемента ИП.

Таким образом, в рамках сектора трансфера технологий (второго элемента структуры национальной инновационной системы «Инновационная инфраструктура», см. табл. 1) формируется инфраструктурная и информационная подсистемы РИС, обеспечивающие реализацию ресурсного элемента ИП.

Вычленение производственно-технологической подсистемы в структуре РИС обусловлено тем, что промышленная специализация региона, образуя производственно-технологическую сеть, способствует реализации основных направлений промышленного и технологического развития территории, развитию производственно-технологических связей, переходу на новые технологии, продвижению технологий и инноваций на рынок, тем самым обеспечивая результат реализации ИП.

Вследствие того, что ресурсное обеспечение развивает новые виды предприятий и новые виды производств, следовательно целесообразно выделить ресурсную и кластерно-отраслевую подсистемы в структуре РИС, обеспечивающие результат реализации ИП.

Таким образом, в рамках сектора коммерциализации нововведений (третьего элемента структуры национальной инновационной системы «Предпринимательский сектор», см. табл. 1) формируется производственно-технологическая, ресурсная и кластерно-отраслевая подсистемы РИС, обеспечивающие результат реализации ИП.

Исходя из вышеизложенного, структурируем РИС на следующие подсистемы [Гуриева, 2007, с. 146]:

- институциональную, организационноуправленческую, финансово-инвестиционную, которые создают внешние возможности и мотивационные стимулы для реализации ИП;

- научно-исследовательскую и образовательную, обеспечивающие внутренние возможности реализации ИП;

- инфраструктурную и информационную, реализующие ресурсный элемент ИП;

- производственно-технологическую, кластерно-отраслевую и ресурсную, обеспечивающие результат реализации ИП. 
Уровни внутрисистемных отношений между отдельными элементами подсистем отражены в таблице 2.

В структуре РИС обозначим систему управления реализацией ИП на региональном уровне (см. рис. 2).

Управление реализацией ИП региона является частью всей системы управления регионом, что предполагает целесообразность построения институционально-организационной структуры управления реализацией ИП РИС, имеющей иерархическое строение и состоящей из указанных выше подсистем.

Основными целями управления реализацией ИП являются (см. табл. 2):

1. Уровень 1 «Управление-регулирование» - формирование соответствующей институциональной среды.

2. Структурный блок «Генерация знаний»повышение качества образования и уровня научно-исследовательской деятельности регионов.

3. Структурный блок «Инновационная инфраструктура» - повышение эффективности деятельности инфраструктурного элемента ИП.

4. Структурный блок «Предпринимательский сектор» - реализация инновационной политики субъектов хозяйствования и повышение уровня научно-технического развития регионов ЮФО.

Содержание факторов инновационной деятельности представлено в виде иерархической структуры трансформационными и трансакционными макрофакторами, системное единство которых определяет усвоение каждого из них в процессе инновационной деятельности и максимизирует ее эффективность.

Субъектами управления являются различные подразделения в органах государственной власти субъекта РФ.

Объектами управления выступают организации региона, занятые инновационным производством, развитием и использованием инновационных ресурсов региона, формированием и использованием инновационной инфраструктуры, подготовкой и переподготовкой кадров в сфере инновационного производства региона, способствующие формированию, развитию и реализации ИП региональной экономики. Субъектами управления (см. рис. 2) федерального значения первого уровня струк- туры инновационной системы являются Совет по науке и высоким технологиям при Президенте РФ, Минобрнауки РФ, Роспатент, ФАНИ, Министерство Финансов РФ и др. На региональном уровне субъекты управления представлены соответствующими подразделениями в органах государственной власти субъекта РФ. Субъекты управления федерального значения структурного блока «Генерация знаний» представлены Минобрнауки РФ, РАН, РФФИ, РГНФ и др., а региональный уровень - соответствующими подразделениями и отделениями в государственных структурах субъекта РФ.

Субъекты управления федерального значения структурного блока «Инновационная инфраструктура» представлены Министерством информационных технологий и связи, ЦТТ, ИТЦ и др., а региональный уровень соответствующими подразделениями в государственных структурах субъекта РФ.

Субъектами управления федерального значения структурного блока «Предпринимательский сектор» являются: Министерство экономического развития и торговли, Министерство промышленности и энергетики, где региональный уровень представлен соответствующими подразделениями в государственных структурах субъекта РФ [Инновационная Россия - 2020..., 2010].

Таким образом, субъекты, осуществлявшие управленческое воздействие на отношения в инновационной сфере, условно можно разделить на три группы. На федеральном уровне таким органом является Министерство образования и науки РФ, которое осуществляет указанную политику через три исполнительных агентства [Национальные инновационные системы..., 2006, с. 45].

Ко второй группе субъектов управления, в рамках которых контролируются и распределяются средства на НИОКР, относятся: Министерство промышленности и энергетики, контролирующее через Федеральное агентство по промышленности военные и промышленные НИОКР; Министерство экономического развития, финансирующее прикладные экономические исследования; Министерство информационных технологий и связи, контролирующее бюджет НИОКР в области информационных технологий. 
Характеристика структурных компонентов региональной инновационной системы ЮФО

\begin{tabular}{|c|c|c|}
\hline $\begin{array}{c}\text { Структурные } \\
\text { блоки РИС }\end{array}$ & Подсистемы РИС & $\begin{array}{c}\text { Результативность РИС / } \\
\text { Формирование и реализация ИП }\end{array}$ \\
\hline $\begin{array}{l}\text { Уровень } 1- \\
\text { «осударст- } \\
\text { венное управ- } \\
\text { ление / регу- } \\
\text { лирование» }\end{array}$ & $\begin{array}{l}\text { Институциональ- } \\
\text { ная } \\
\text { Организационно- } \\
\text { управленческая } \\
\text { Финансово- } \\
\text { инвестиционная }\end{array}$ & 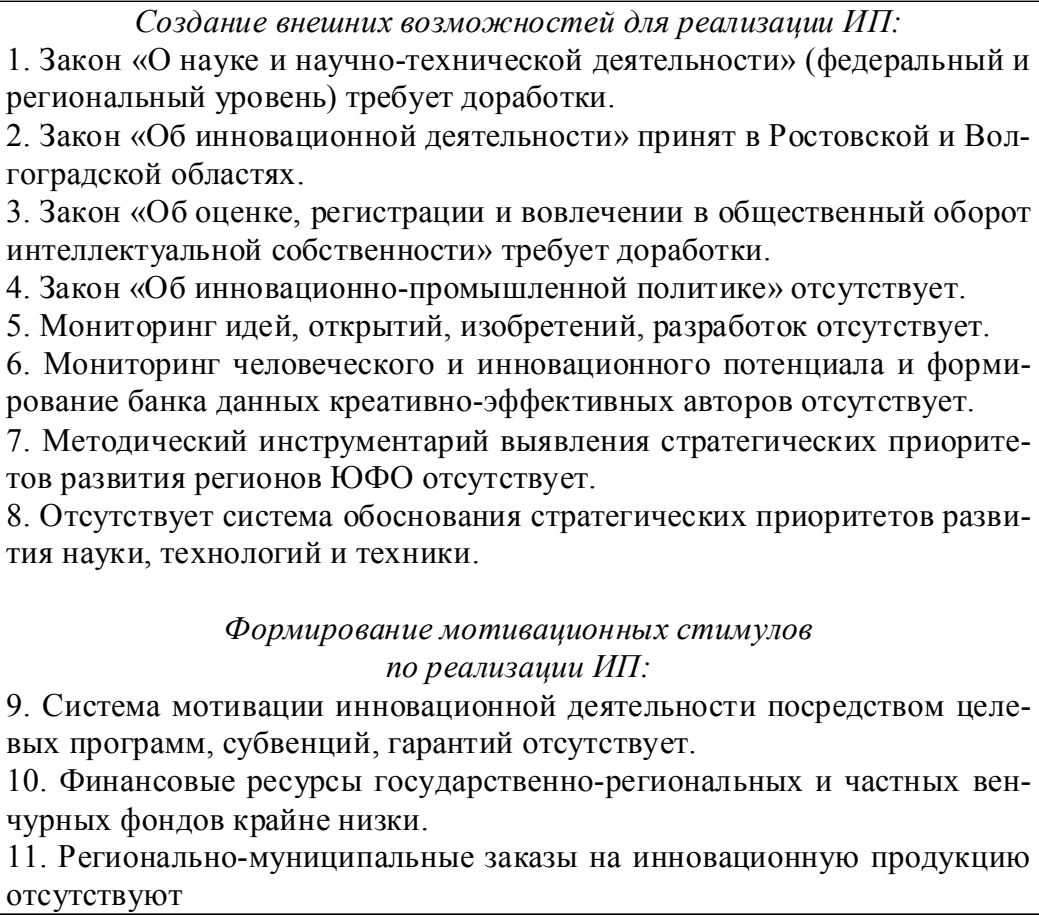 \\
\hline $\begin{array}{l}\text { «Генерация } \\
\text { знаний» }\end{array}$ & $\begin{array}{l}\text { Образовательная } \\
\text { Научно-исследо- } \\
\text { вательская }\end{array}$ & $\begin{array}{l}\text { Создание внутренних возможностей реализации ИП: } \\
\text { 1. Наукоемкость регионов ЮФО - низкая. } \\
\text { 2. Видовая структура исследований и разработок в ЮФО не отвечает } \\
\text { пропорциям развития производства. } \\
\text { 3. Затраты на исследования и разработки в расчете на } 1000 \text { руб. ВРП - } \\
\text { низкие }\end{array}$ \\
\hline $\begin{array}{l}\text { «Инноваци- } \\
\text { онная инфра- } \\
\text { структура» }\end{array}$ & $\begin{array}{l}\text { Инфраструктур- } \\
\text { ная } \\
\text { Информационная }\end{array}$ & $\begin{array}{l}\text { Реализация ресурсного элемента ИП: } \\
\text { 1. Преимущественная ориентация процесса распространения знаний на } \\
\text { внутренний рынок. } \\
\text { 2. Низкая активность приобретения патентов, ноу-хау и лицензий. } \\
\text { 3. Деятельность ИТЦ в ЮФО характеризуется как неэффективная. } \\
\text { 4. Передача технологий и их коммерциализация ЦТТ ЮФО не осущест- } \\
\text { вляется }\end{array}$ \\
\hline $\begin{array}{l}\text { «Предприни- } \\
\text { мательский } \\
\text { сектор» }\end{array}$ & $\begin{array}{l}\text { Производственно- } \\
\text { технологическая } \\
\text { Кластерно-отрас- } \\
\text { левая } \\
\text { Ресурсная }\end{array}$ & $\begin{array}{l}\text { Результат реализации ИП: } \\
\text { 1. Уровень инновационной активности организаций ЮФО остается } \\
\text { крайне низким. } \\
\text { 2. Конкурентоспособность исследований и разработок регионов ЮФО } \\
\text { на мировом рынке низкая. } \\
\text { 3. По числу созданных передовых производственных технологий ЮФО } \\
\text { занимает одно из последних мест среди субъектов РФ. } \\
\text { 4. В технопарках ЮФО не происходит кластеризации нововведений и } \\
\text { не формируются взаимосвязанные предприятия в рамках кластера. } \\
\text { 5. Доля инновационной продукции в общем объеме отгруженной про- } \\
\text { дукции незначительна }\end{array}$ \\
\hline
\end{tabular}

Примечание. Составлено автором. 


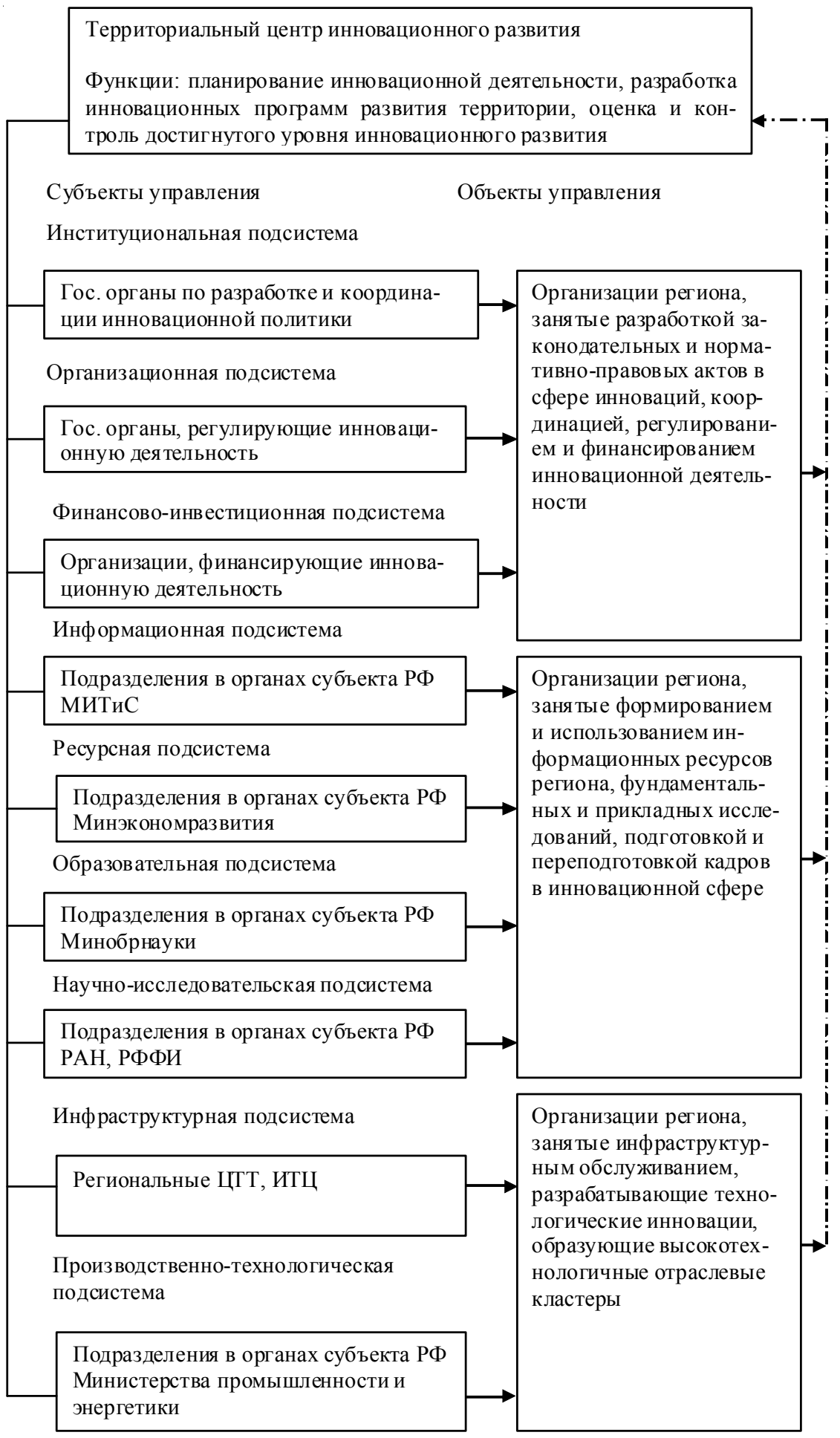

Рис. 2. Институционально-организационная структура управления реализацией ИПРИС

Примечание. Составлено автором. 
Третья группа субъектов управления процессами инновационного развития представлена структурными подразделениями администраций и региональных правительств.

Таким образом, первым компонентом структуры управления реализацией ИП региональной экономики (см. рис. 2) выступает институциональная подсистема, складывающаяся под воздействием федерального и регионального законодательства в инновационной сфере.

Согласно табл. 2 указанную компоненту РИС целесообразно совершенствовать. Закон «Об инновационной деятельности» среди регионов ЮФО принят только в Ростовской и Волгоградской областях, а Закон «Об инновационно-промышленной политике» вовсе отсутствует.

Исследуя указанную подсистему РИС в рамках структуры управления реализацией ИП региональной экономики, автор пришел к выводу о необходимости дополнения системы правовых методов, регулирующих инновационные отношения, обеспечивающие правовую основу стимулирующего воздействия на предпринимательскую активность инновационной сферы, способствующую формированию внешних возможностей для реализации ИП региональной экономики.

Вторым компонентом предложенной структуры выступает организационная подсистема, которую согласно табл. 2 целесообразно совершенствовать по причине отсутствия системы мониторинга идей, открытий, изобретений, регионов ЮФО. Анализ указанной подсистемы РИС показал, что в ЮФО необходим инструмент в виде технологической платформы, позволяющий идентифицировать возможности и способности регионов ЮФО в реализации ИП.

Третьим компонентом структуры управления реализацией ИП региональной экономики является финансово-инвестиционная подсистема, которую согласно табл. 2 целесообразно совершенствовать по причине отсутствия системы мотивации инновационной деятельности посредством целевых программ, субвенций, гарантий, регионально-муниципальных заказов на инновационную продукцию, а также недостаточным уровнем финансирования государственными и частными венчурны- ми фондами региональной экономики. Автором в рамках исследования указанной подсистемы РИС выявляются финансовые возможности регионов ЮФО, обеспечивающие реализацию ИП региональной экономики.

Четвертым компонентом предложенной структуры выступают образовательная и научно-исследовательская подсистемы, которые согласно табл. 2 целесообразно совершенствовать по причине низкого уровня наукоемкости регионов ЮФО и затрат на исследования и разработки. Автором в рамках исследования указанной подсистемы РИС исследуются динамика и перспективы развития интеллектуального потенциала регионов ЮФО, что позволяет определить степень влияния экономики знаний на ВРП и охарактеризовать внутренние возможности реализации ИП региональной экономики.

Пятым компонентом предложенной структуры выступают инфраструктурная и информационная подсистемы РИС, которые характеризуют управление механизмом передачи знаний и обеспечивают реализацию ресурсного элемента ИП РИС.

Согласно табл. 2 указанная компонента РИС нуждается в совершенствовании по причине низкой эффективности деятельности ИТЦ и ЦТТ ЮФО в передаче технологий и их коммерциализации. Автором в рамках исследования указанной подсистемы РИС выявляются проблемы реализации ИП регионов ЮФО посредством инновационной инфраструктуры, пути решения указанных проблем, а также возможности информационного фактора в формировании стратегии реализации ИП регионов ЮФО.

Шестым компонентом структуры управления реализацией ИП региональной экономики является производственно-технологическая подсистема, которую в целях обеспечения результата реализации ИП РИС целесообразно совершенствовать по причине низкого уровня инновационной активности организаций ЮФО, конкурентоспособности исследований и разработок регионов ЮФО на мировом рынке, а также отсутствия положительной динамики в создании передовых производственных технологий ЮФО среди субъектов РФ. Автором в рамках исследования указанной подсистемы РИС выявляются возможно- 
сти технико-технологического фактора в формировании стратегии реализации ИП регионов ЮФО.

Седьмым компонентом структуры управления реализацией ИП региональной экономики является кластерно-отраслевая подсистема, обеспечивающая координацию и регулирование процессов формирования и развития территориальных комплексов наукоемких отраслей и превращения их в кластеры, что также обеспечивает результат реализации ИП РИС.

Согласно табл. 2 указанную компоненту РИС необходимо совершенствовать по причине отсутствия кластеризации нововведений в регионах ЮФО, что не обеспечивает формирования взаимосвязанных предприятий в рамках кластера. Автором в рамках исследования указанной подсистемы РИС определяются перспективы территориальных комплексов наукоемких отраслей, обозначается необходимость превращения их в кластеры на территории региона.

Восьмым компонентом структуры управления реализацией ИП региональной экономики является ресурсная подсистема, позволяющая определить возможности ресурсного фактора в формировании стратегии реализации ИП регионов ЮФО.

Одним из узких мест РИС является низкий уровень развития инновационной инфраструктуры ЮФО, который не обеспечивает связь науки с производством. В соответствии с этим координационно-регулирующие функции могли бы взять на себя областные межотраслевые и отраслевые инновационные центры с филиалами в муниципальных образованиях с высокой концентрацией ИП.

Следовательно, для эффективного управления РИС необходим региональный центр координации инновационной деятельности. Взаимодействие между элементами подсистемы происходит посредством ряда механизмов административного, регулирующего, инвестиционного, институционального воздействия.

\section{Выводы}

Структура современной НИС представлена совокупностью организаций, создающих, внедряющих и передающих знания и навыки, а также институтов правового, финансового и социального характера, где РИС как подсистема НИС объединяет функции сферы исследований и разработок с территориально-отраслевой структурой и соответствующим механизмом управления. НИС, как организационная форма развития и реализации ИП, создает внешние возможности его использования (первый элемент ИП), формирует мотивационные стимулы к инновационной деятельности (второй элемент ИП), создает внутренние возможности воспроизводства инновационной деятельности (третий элемент ИП), формирует способность по мобилизации ресурсной составляющей ИП (четвертый элемент ИП), обеспечивает постановку и серийное производство инноваций (пятый элемент ИП).

РИС состоит из подсистем, отражающих территориальное развитие условий и факторов производства и обеспечивающих внешние и внутренние возможности реализации ИП.

Структуризация РИС проведена по субъектам и уровням инновационной деятельности. Структура системы состоит из элементов, объединенных в определенные блоки, которые рассматриваются как подсистемы с иерархическими связями между ними.

\section{СПИСОК ЛИТЕРАТУРЫ}

Гуриева, Л. К. Стратегия инновационного развития экономики региона: теория и методология : монография / Л. К. Гуриева ; под. ред. д-ра экон. наук, проф. К. И. Плетнева ; Сев.Осет. гос. ун-т. - Владикавказ : Изд-во СОГУ, 2007. $-508 \mathrm{c}$.

Демидов, В. А. Региональная инновационная система: потенциал и тенденции развития / В. А. Демидов, Н. Н. Лебедева, О. С. Олейник. - Волгоград : Изд-во ВолГУ, 2008. - 318 с.

Егоров, Е. Г. Научно-инновационная система региона: структура, функции, перспективы развития / Е. Г. Егоров, Н. В. Бекетов. - М. : Academia, 2002. $-224 \mathrm{c}$.

Егорова, М. В. Модель региональной инновационной системы: теоретико-методологический аспект / М. В. Егорова, В. В. Авилова // Инновации. - 2007. - № 6. - С. 66-69.

Инновационная Россия - 2020. Стратегия инновационного развития Российской Федерации на 
период до 2020 г. Минэкономразвития России. - М. : [б. и.], 2010. -230 с.

Иншаков, О. В. Теория факторов производства в контексте экономики развития : научный доклад на Президиуме МАОН (г. Москва, 29 ноября 2002 г.) / О. В. Иншаков. - Волгоград : Изд-во ВолГУ, 2002. - 92 с.

Маренков, Н. Л. Инновации : учеб. пособие / Н. Л. Маренков. - М. : Изд-во нац. ин-та бизнеса, 2004. $576 \mathrm{c}$.

Национальные инновационные системы в России и ЕС / под ред. В. В. Иванова. - М. : ЦИПРАН PAH, 2006. $-280 \mathrm{c}$.

Industrial Relations As a Key to Strengthening Innovation in Europe // European Commission. Innovation Paper. Directorate-General for Enterprise. EUR 17060. - 2003. - № 36. - P. 45.

\section{REFERENCES}

Gurieva L.K. Strtegiya innovatsionnogo razvitiya ekonomiki regiona: teoriya i metodologiya: monografiya [Strategy of Innovation Development of Regional Economy: Theory and Methodology. Monograph]. Vladikavkaz, Izd-vo SOGU, 2007. 508 p.

Demidov V.A., Lebedeva N.N., Oleynik O.S. Regionlnaya innovatsionnaya sistema: potentsial $i$ tendentsii razvitiya [Regional Innovation System: Capacity and Development Trends]. Volgograd, Izd-vo VolGU, 2008. 318 p.

Egorov E.G., Beketov N.V. Nauchno-innovatsionnaya sistema regiona: struktura, funktsii, perspektivy razvitiya [Knowledge and Innovation System of the Region: Structure,
Functions, Development Trends]. Moscow, Academia Publ., 2002. 224 p.

Egorova M.V., Avilova V.V. Model regionalnoy innovatsionnoy sistemy: teoretikometodologicheskiy aspect [The Model of Regional Innovation System: Theory and Methodology]. Innovatsii [Innovations], 2007, no. 6, pp. 66-69.

Innovatsionnaya Rossiya - 2020. Strategiya innovatsionnogo razvitiya Rossiyskoy Federatsii na period do $2020 \mathrm{~g}$. Minekonomrazvitiya Rossii [Sstrategy of Innovative Development of the Russian Federation for the Period Until 2020. Ministry of Economic Development of Russia]. Moscow, 2010. 230 p.

Inshakov O.V. Teoriya faktorov proizvodstva $v$ kontekste ekonomiki razvitiya: nauchnyy doklad na Prezidiume MAON (g. Moskva, 29 noyabrya 2002 g.) [Production Factors Theory in the Context of Development Economics: Scientific Report at the Presidium of the International Academy of Organizational Sciences (Moscow, November 29, 2002)]. Volgograd, Izd-vo VolGU, 2002. 92 p.

Marenkov N.L. Innovatsii: ucheb. posobie [Innovations. Textbook]. Moscow, Izd-vo natsionalnogo instituta biznesa, 2004. $576 \mathrm{p}$.

Natsionalnye innovatsionnye sistemy $v$ Rossii $i$ ES [National Innovation Systems in Russia and the European Union]. Moscow, TsIPRAN RAN, 2006. 280 p.

Industrial Relations As a Key to Strengthening Innovation in Europe. European Commission. Innovation Paper. Directorate General for Enterprise. EUR 17060, 2003, no. 36, p. 45.

\section{Information About the Author}

Igor V. Antonenko, Candidate of Sciences (Economics), Associate Professor, Department of Economic Theory, World and Regional Economics, Volgograd State University, Prosp. Universitetsky, 100, 400062 Volgograd, Russian Federation, AntonenkoIV@volsu.ru, https://orcid.org/0000-0002-8379-3477

\section{Информация об авторе}

Игорь Владимирович Антоненко, кандидат экономических наук, доцент, кафедра экономической теории, мировой и региональной экономики, Волгоградский государственный университет, просп. Университетский, 100, 400062 г. Волгоград, Российская Федерация, AntonenkoIV@volsu.ru, https://orcid.org/0000-0002-8379-3477 